\title{
ФИЛОЛОГИя
}

DOI: 10.17805/ggz.2018.3.4

\section{Образ Кристофера Марло и псевдобиографический подход в современной массовой культуре ${ }^{*}$ \\ Н. В. Захаров \\ Московский гуманитарный университет}

В статье ставится проблема соотношения биографического и псевдобиографического методов интерпретации образа Кристофера Марло в современной массовой культуре, на сиене и экране. По мнению автора, мифобиографический подход наиболее востребован в развлекательной популярной культуре, ориентированной на массового потребителя.

Ключевые слова: К. Марло; современники Шекспира; биографический метод; псевдобиографический метод; псевдобиография; мифобиографический подход

\section{The Image of Christopher Marlowe and the Pseudo-Biographical Approach in Contemporary Mass Culture}

N. V. Zakharov

Moscow University for the Humanities

The article raises the problem of correlation between the biographical and pseudo-biographical methods for interpreting the image of Christopher Marlowe in contemporary mass culture, on stage and screen. In the author's view, the mytho-biographical approach is mainly applied in entertaining popular culture oriented to the mass consumer.

Keywords: C. Marlowe; Shakespeare's contemporaries; biographical method; pseudo-biographical method; pseudo-biography; mytho-biographical approach

Кристофер Марло получил широкую известность и благодаря тому, что это один из талантливейших представителей ренессансной драматургии

\footnotetext{
* Статья подготовлена в рамках проекта «Кристофер Марло и его творчество в русской и мировой культуре: междисциплинарный взгляд» при финансовой поддержке Российского фонда фундаментальных исследований (грант № 18-012-00679).

The article was prepared within the framework of the project "Christopher Marlowe and His Literary Heritage in Russian and World Culture: An Interdisciplinary Look" with financial support from the Russian Foundation for Basic Research (grant No. 18-012-00679).
} 
«университетских умов» Англии XVI в., и благодаря тому, что его имя тесно связано с именем Уильяма Шекспира: его называют предшественником Шекспира (Дживелегов, 1943; Луков, 2010: Электронный ресурс), а некоторые шекспироведы считают, что это и был Шекспир, не убитый, а счастливо спасшийся и продолжавший творить под ставшим всемирно известным именем.

Биографический метод не часто используется в художественной литературе о жизни и творчестве К. Марло, чего нельзя сказать о псевдобиографическом или мифобиографическом подходах, которые применяют большинство писателей, придумывая различные мистификации и модифицируя известные биографические факты. Сформировался метод альтернативной биографии. Например, Э. Бёрджесс (Бёрджесс, 2001, 2002, 2015) нашел в лице Марло превосходный материал для позиционирования своих идей в современных условиях (см.: Захаров, Гайдин, 2010-; Галахова, 2016; Львов, 2016). И хотя почти всегда драматург выступает в роли демонического бунтаря, шпиона и

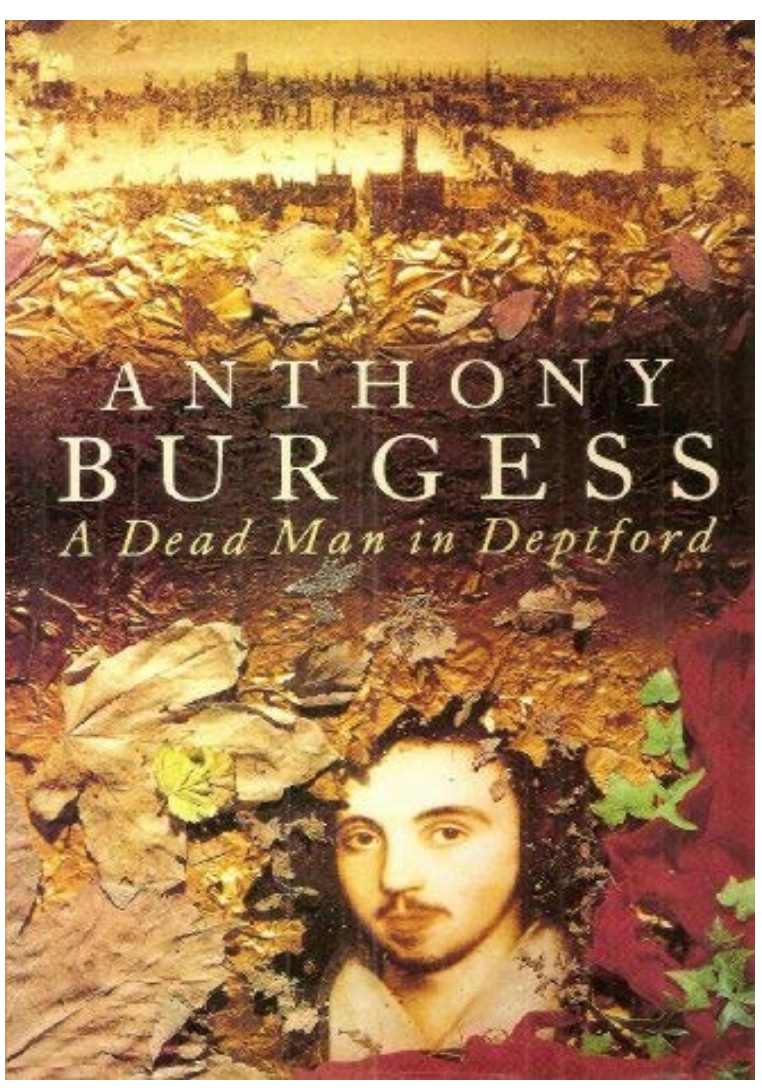
даже содомита, его образ в массовой культуре не столь однобок. Действительно, прежде всего, Марло - заблудший, мечущийся поэт-нигилист, атеист, подчас сатанист и богохульник, что, в общем-то, соответствует его репутации среди врагов; во всяком случае, именно таким он предстает в текстах допросов Тайного совета, которые резко контрастируют с отзывами и воспоминаниями его друзей по писательскому цеху.

Другой его образ, созданный фантазией сценаристов М. Нормана (M. Norman) и Т. Стоппарда (T. Stoppard), — герой в фильме «Влюбленный Шекспир» (Shakespeare in Love, 1998 г., режиссер Дж. Мэдден / J. Madden; cм., например: Гайдин, 2014ab). Здесь образ К. Марло в исполнении Р. Эверетта (R. Everett), напротив, предельно романтизирован, он, пожалуй, самый одухотворенный из всех героев, творящих для сцены театра «Роза». Кит не только самый успешный в те годы английский драматург, но и благородный интеллектуал, искренний товарищ Шекспира. Именно он протягивает руку помощи утратившему вдохновение будущему Барду, дарит ему сюжет и подсказывает придать итальянский колорит пьесе «Ромео и Джульет- 
та»: молодой повеса Ромео влюбляется в дочь своего врага, а его лучший друг Меркуцио погибает на дуэли от рук брата его возлюбленной Этель (там же; см. видео: https://youtu.be/foOquPn1L60).

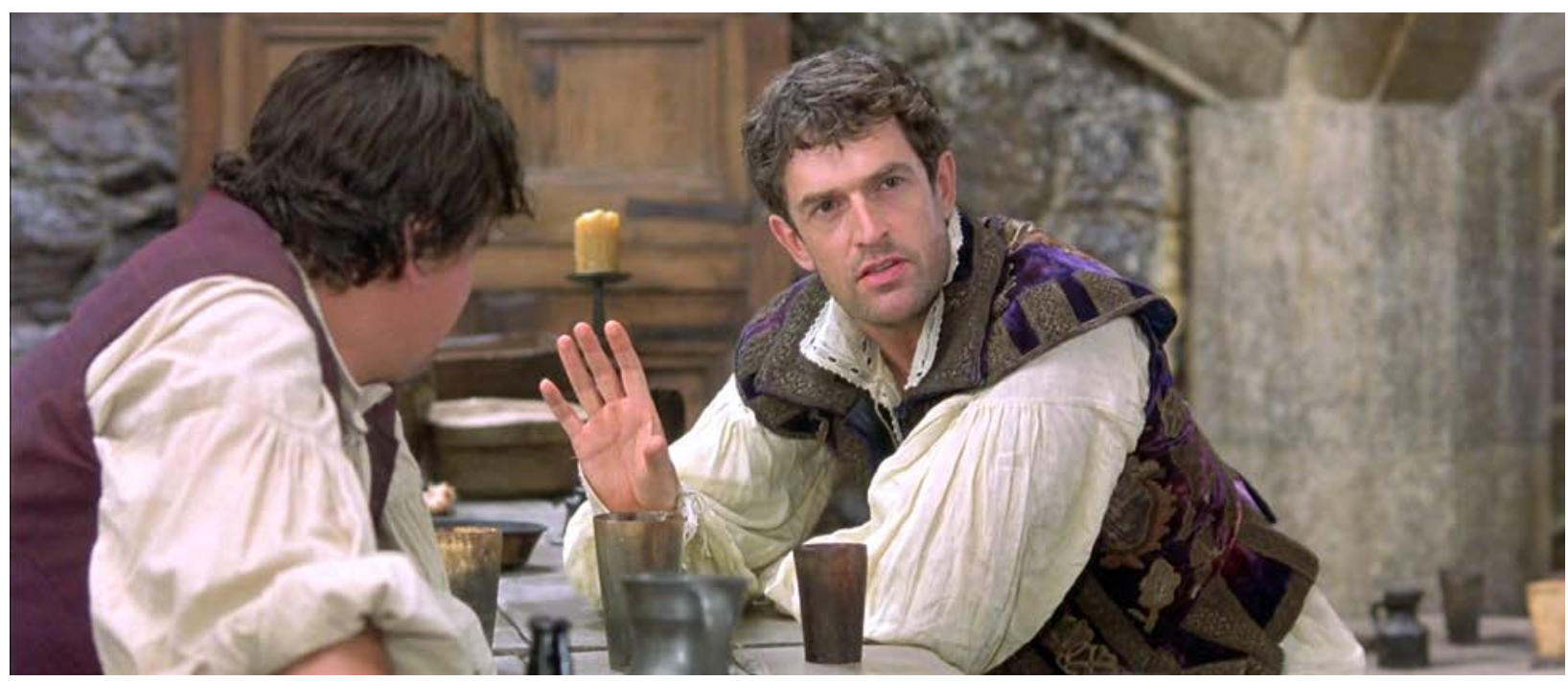

Руперт Эверетт в роли Марло в фильме «Влюбленный Шекспир»

Правда, вымышленный сценаристами неблагодарный Шекспир отплатил другу постыдным предательством и стал косвенной причиной его гибели. Узнав о смерти Марло, Шекспир винит себя, и миф о том, что Кит оказался жертвой заговора, приобретает совсем другое звучание. По своей эмоциональной насыщенности короткая эпизодическая роль становится чуть ли не самым драматичным моментом всей двухчасовой картины.

В 2014 г. на лондонской сцене театра Ноэла Кауарда (Noël Coward Theatre) была представлена одноименная постановка популярного в России режиссера Д. Доннеллана (D. Donnellan) в театральной обработке Л. Холла (L. Hall). Спектакль получил положительные рецензии ведущих английских критиков (Bassett, 2014; Billington, 2014; Cain, 2014; Letts, 2014; Spencer, 2014; Taylor, 2014). Значительно меньше изданий выступило с критикой фан-

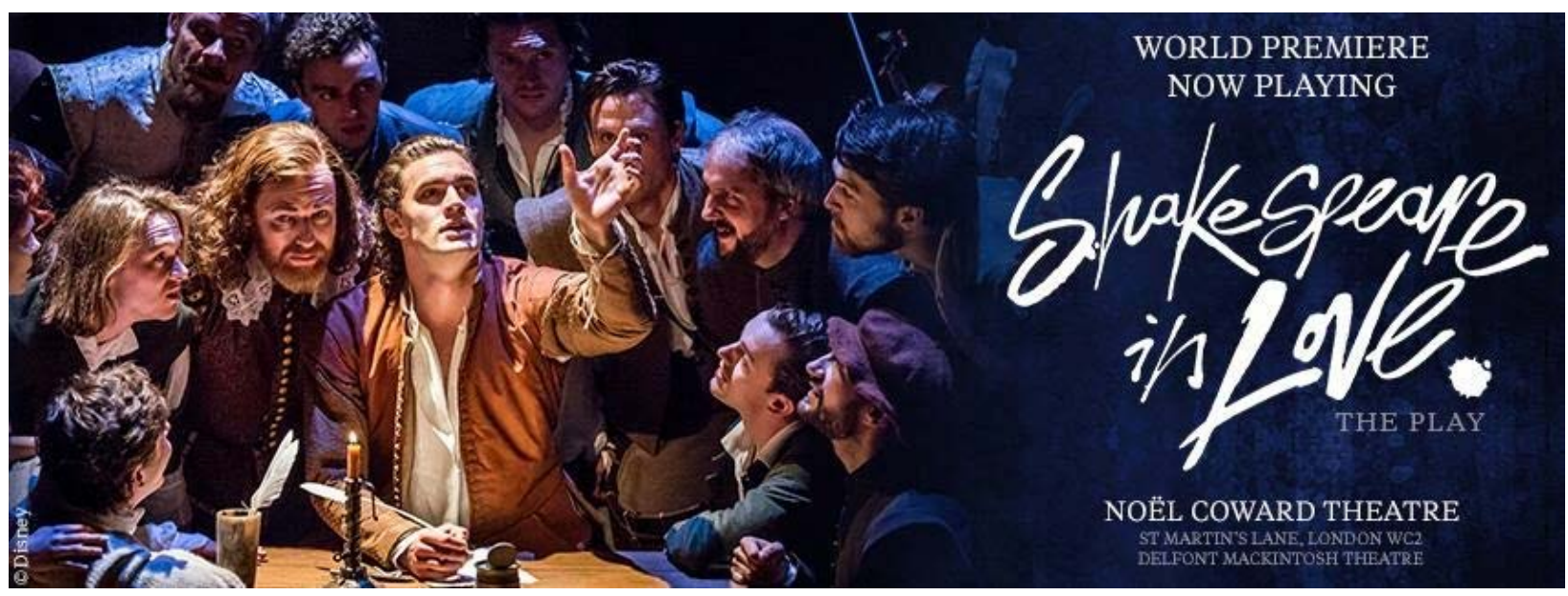


тазии Т. Стоппарда и М. Нормана. Например, по мнению Л. Пёрвз, хотя фильм Дж. Мэддена и был «поп-халтурой» (“pop-schlock ”) со слоганом «Любовь - единственное вдохновение» (“Love is the only inspiration”), но все недостатки компенсировались стоппардовским талантом, а в спектакле даже театральное остроумие не помогало поверить в величественные слова, исходящие из уст полного жалости к самому себе Шекспиру (“it dangerously hard to believe in the great words and sentiments emanating from him”) (Purves, 2014: Электронный ресурс).

Спустя четыре года успех постановки дошел до Москвы: свою версию спектакля Д. Доннеллана представил Е. А. Писарев на сцене Московского драматического театра им. А. С. Пушкина. Режиссер пригласил на роль Марло харизматичного А. В. Кузичева. Ранее он уже исполнял шекспировские роли в доннеллановских спектаклях (Виола в «Двенадцатой ночи», Ариэль в «Буре») и даже был номинирован на премию «Золотая маска» 2015 г. за роль Анджело в «Мере за меру» в номинации «Лучшая мужская роль». Кит Марло в его исполнении получился вдохновенным и дерзновенным поэтом, «отмеченным печатью трагической судьбы», вкладывающий в уста Уилла строчки из его же сонетов (Карась, 2018: Электронный ресурс).

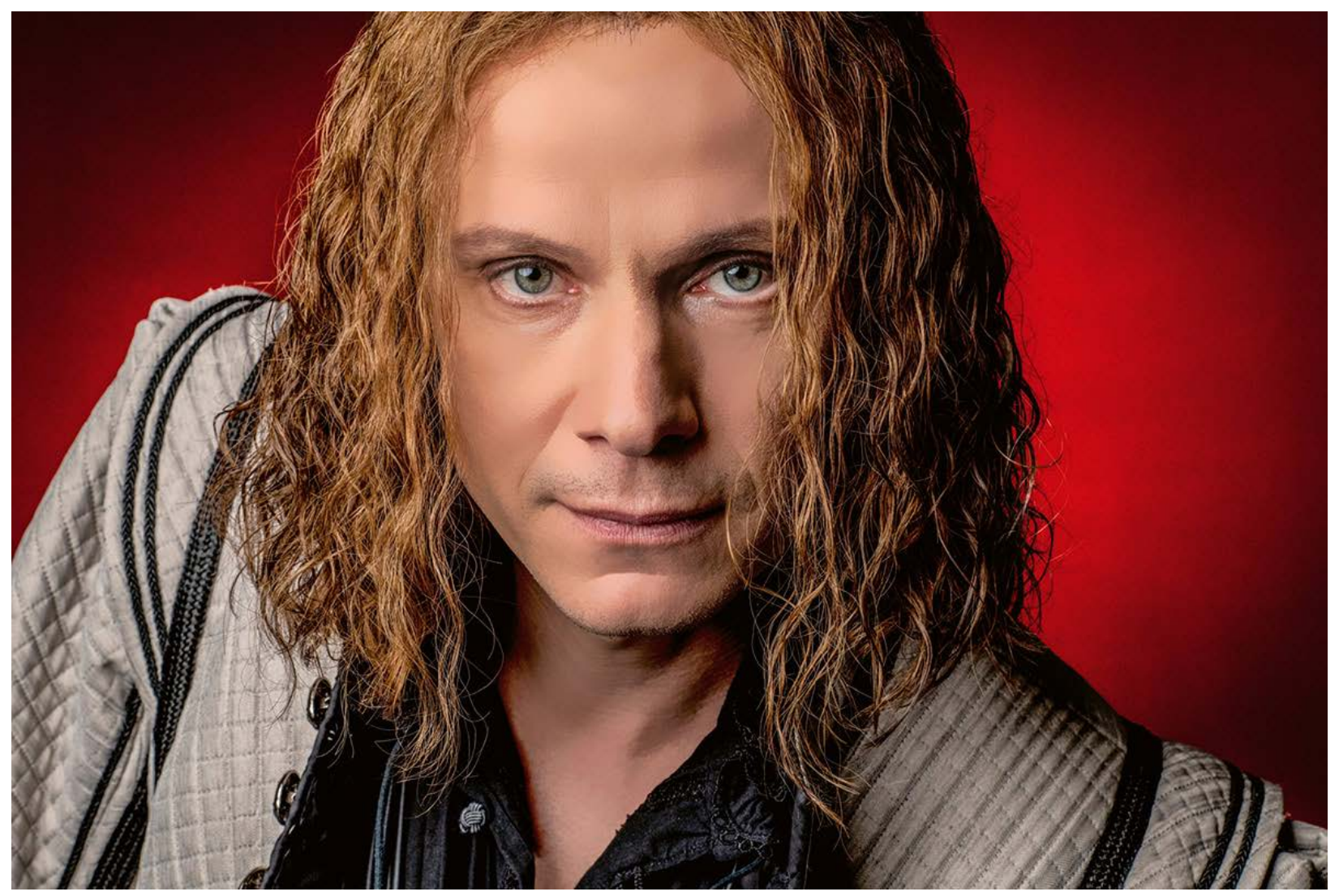

Андрей Кузичев в роле Кристофера Марло

Таким образом, популяризованный создателями фильма миф о жизни и творчестве молодого Шекспира и его современников спустя 20 лет начал 
функционировать на театральных подмостках совершенно в ином контексте. Поле деятельности Марло в спектакле значительно шире, чем в ставшем уже классическим оскароносном фильме.

В фильме «Аноним» (Anonymous) голливудского режиссера Р. Эммериха (R. Emmerich) 2011 года эксплуатируется, пожалуй, наиболее популярная из всех антистратфордианских теорий в России, а именно та, согласно которой пьесы, приписываемые Шекспиру, якобы были написаны аристократом графом Оксфордом Эдуардом де Вером (Earl of Oxford Edward de Vere).

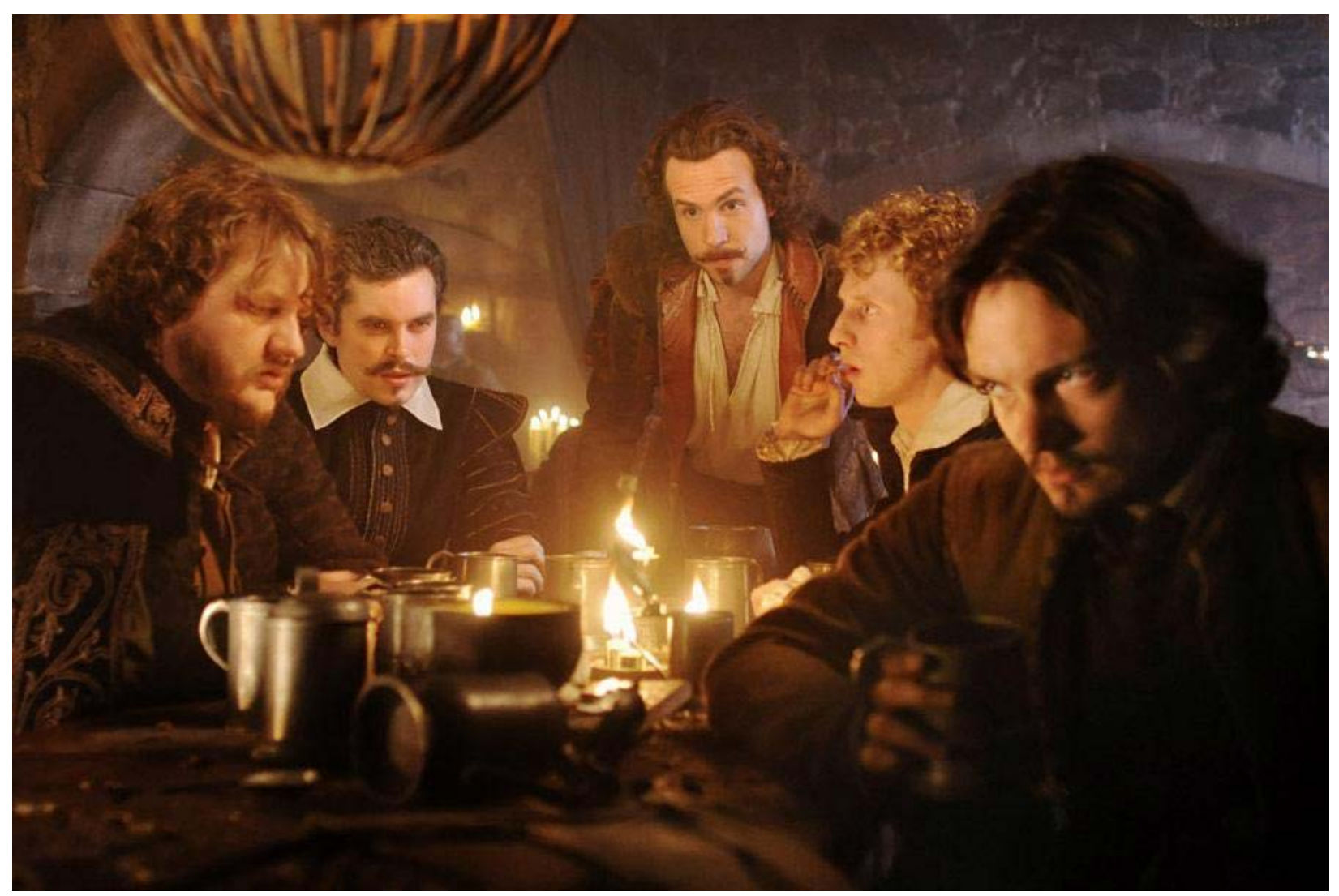

Тристан Гравель (второй слева) в роли Кристофера Марло в фильме «Аноним»

Согласно фантазии создателей фильма, Марло (Т. Гравель / T. Gravelle) раскрывает тайный заговор де Вера и Бена Джонсона, который отказался от роли подставного драматурга и звезды лондонской сцены № 1. Однако предназначенные ему пьесы попадают в руки алчного пьянчужки и фигляра Шекспира. В результате, опасаясь быть изобличенным, коварный граф Оксфорд нанимает молодого провинциального актера убить Марло, что тот и делает в пьяной драке. Все эти выдумки не выдерживают никакой критики, поскольку исторический Марло погиб в 1593 г., а Кит Эммериха жив до неудачного восстания под предводительством графа Эссекса Роберта Деверё, которое тот возглавил против Елизаветы I в 1601 г.

В приниженном, но положительном контексте изображается Марло в комическом сериале (Upstart Crow в русском переводе «Уильям наш, Шекс- 
пир»). Первый сезон сериала в 2016 г. на ВВС 2 был приурочен к 450-летию со дня смерти всемирно известного драматурга. 29 августа 2018 г. запланирован выход на экраны первой серии третьего сезона. Созданный в альянсе режиссеров Р. Бодена (R. Boden) и М. Липси (M. Lipsey) с прославленным сценаристом Б. Элтоном (B. Elton; автор сериалов «Черная гадюка», «Мистер Бин» и др.), сериал стал заметным событием юбилейного шекспировского марафона. Марло в исполнении Т. Дауни (Tim Downie) - верный товарищ и соперник Шекспира по театральному цеху, более опытный, с налетом светской манерности лондонец. Он хитрее, если не умнее выходца из Стратфорда. В целом, Кит ведет праздный, вполне богемный образ жизни, волочится за молоденькими женщинами, а в промежутках и с некоторой ленцой и даже известной долей шалопайства исполняет шпионские обязанности. Вместе с тем, он верен дружбе с Шекспиром, постоянно выручает своего неловкого приятеля из разных неприятных ситуаций, но его абсолютно не интересует литературное творчество как таковое. Все, что он желает, - это гедонистическое прожигание жизни, временами он шантажирует своего амбициозного, но пока еще неизвестного друга, пытаясь выпросить у того готовую пьесу, чтоб выдать ее за свое творение. В статье в газете «Гардиан» критик Дж. Дагдейл (J. Dugdale) удачно окрестил Марло псевдодраматургом (pseudo-playwright), так как в противоположность модной марловианской теории именно Шекспир представлен автором произведений Марло, а не наоборот. Псевдонаучный антишекспировский миф подвергся культурной инверсии, и Марло оказался не «Шекспиром», а изворотливым, но милосердным елизаветинским агентом 007 (Dugdale, 2016). Ему чужды жадность и тщеславие Барда-деревенщины, у него все есть, и ему с легкостью дается любое начинание: щеголь Марло способен в два присеста выучить итальянский язык и влюбить в себя любую аристократку или дочку хозяйки постоялого двора. Ненавязчивый нарциссизм Кита не переходит в патологическое самолюбование, он - легкомысленный повеса и удачливый светский лев.

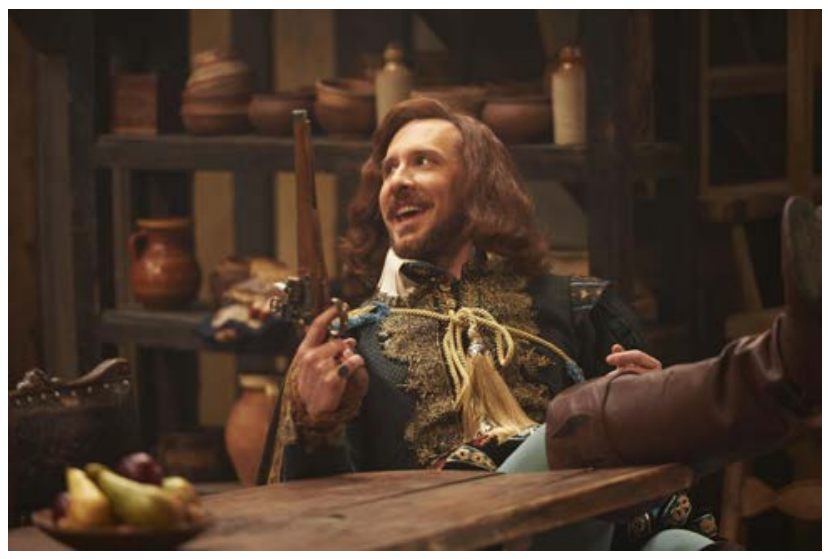

Тим Дауни в роли Кристофера Марло в сериале Upstart Crow 
Соответственно, жанр комедии для интеллектуалов подразумевает необходимость неплохого знакомства не только с творчеством Шекспира (сериал изобилует постоянными цитатами из пьес и сонетов драматурга), но и хорошим знанием исторической эпохи, основных моментов его творческой биографии и сплетен о его семейной жизни. Все это с большим юмором и тонким сарказмом обыгрывают создатели «Вороны-выскочки». Особо следует отметить традиционно сильные стороны британского кинематографа: классически высокую культуру режиссуры, профессиональную актерскую игру, замечательную работу композитора и художников по костюмам.

Итак, традиционный в науке и элитарной культуре биографический метод, характерный для изображения и описания жизни и творчества знаменитостей (Луков, 2018), сегодня перестает быть востребованным в искусстве. За последние 30-40 лет он утратил актуальность в массовой культуре и в какойто мере выродился, будучи замещен псевдобиографическими или мифобиографическими способами создания и интерпретации образа К. Марло, более выразительными и яркими, благодаря неправдоподобному вымыслу и гиперболизации событий. Этот процесс в определенной мере имеет культурологическую параллель: он напоминает культурный феномен, получивший название «шекспиросфера» (Луков В., Захаров, Луков Вл., 2012; Луков В., Захаров, Луков Вл., Гайдин, 2012). Шекспиросферу Вл. А. Луков определил как «сфера культуры человечества, содержанием которой является вся совокупность взаимодействий феномена Шекспира как одной из мировых тезаурусных констант с культурной жизнью человечества» (Луков, 2014: 312). Особенность трактовки Марло в этом случае состоит в том, что его имя воспринимается в круге современников Шекспира, и если бы этой связи в массовом восприятии Марло не было, то не было бы и попыток представить его жизнь псевдобиографическими или мифобиографическими способами, поскольку он был бы за пределами узкого профессионального сообщества неузнаваем и потому неинтересен. Но такая параллель есть, она не создает «марлосферы», ибо «шекспиросфера» уникальна для культуры, она транснациональна, не относится только к кругу исследователей творчества Шекспира, а проникла в тезаурусы большого количества людей, далеких от литературоведения и в целом от культурной жизни. Но Марло становится благодаря своему первоисточнику — реально существовавшему Кристоферу Марло — почти исторической фигурой, биография которого, во-первых, малоизвестна, во-вторых, позволяет приписывать ей любые свойства, придумывать события, сохраняя видимость правды. Это по большей части приемлемо для беллетристики, театральных постановок и экранизаций. Именно такой подход более свойствен развлекательной поп-культуре, ориентированной на вкусы и предпочтения массового потребителя. 


\section{СПИСОК ЛИТЕРАТУРЫ}

Бёрджесс, Э. (2001) Шекспир. Гений и его эпоха. М. : Центрполиграф. $383 \mathrm{c}$.

Бёрджесс, Э. (2002) Влюбленный Шекспир. М. : Центрполиграф. 332 с.

Бёрджесс, Э. (2015) Мертвец в Дептфорде : пер. с англ. Л. Иотковской. M. : ACT. 384 c.

Гайдин, Б. Н. (2014а) «Влюбленный Шекспир» [Электронный ресурс] // Электронная энциклопедия «Мир Шекспира». URL: http://world-shake.ru/ru/ Encyclopaedia/4684.html [архивировано в WaybackMachine] (дата обращения: 23.05.2018).

Гайдин, Б. Н. (2014b) Шекспиросфера в современном кино: постановка проблемы [Электронный ресурс] // Информационный гуманитарный портал «Знание. Понимание. Умение». № 4 (июль - август). URL: http://zpujournal.ru/e-zpu/2014/4/Gaydin_Shakespearean-Sphere-Cinema/ [архивировано в WaybackMachine] (дата обращения: 23.05.2018).

Галахова, А. А. (2016) Альтернативная биография Уильяма Шекспира и Кристофера Марло в елизаветинской дилогии Энтони Бёрджесса [Электронный ресурс] // Молодой ученый. № 7. C. 1149-1152. URL: https:// moluch.ru/archive/111/27856/ [архивировано в WaybackMachine] (дата обращения: 23.05.2018).

Дживелегов, А. К. (1943) Глава 6. Марло // История английской литературы. М. ; Л. : Изд-во АН СССР. Т. 1. Вып. 1. 382, [2] с. С. 362-379.

Захаров, Н. В., Гайдин, Б. Н. (2010-) Бёрджесс Энтони [Электронный peсурс] // Энциклопедия «Мир Шекспира». URL: http://world-shake.ru/ru/ Encyclopaedia/3664.html [архивировано в WaybackMachine] (дата обращения: 23.05.2018).

Карась, А. (2018) Гения играет свита [Электронный ресурс] // Российская газета. № 104 (7567). 16 мая URL: https://rg.ru/2018/05/16/reg-cfo/v-teatreim-pushkina-proshla-premera-spektaklia-vliublennyj-shekspir.html [архивировано в WaybackMachine] (дата обращения: 23.05.2018).

Луков, В. А., Захаров, Н. В., Луков, Вл. А. (2012) Шекспиросфера // Захаров, Н. В., Луков, Вл. А. Гений на века: Шекспир в европейской культуре. М. : ГИТР. 504 с. С. 324-336.

Луков, В. А., Захаров, Н. В., Луков, Вл. А., Гайдин, Б. Н. (2012) Шекспиросфера (Шекспир, его современники, его эпоха в культуре повседневности) [Электронный ресурс] // Информационный гуманитарный портал «Знание. Понимание. Умение». № 3 (май — июнь). URL: http://zpu-journal.ru/ e-zpu/2012/3/Lukov Zakharov Lukov Gaydin Shakespeare-sphere/ [архивировано в WaybackMachine] (дата обращения: 23.05.2018). 
Луков, Вл. А. (2010) Английская ренессансная драматургия «университетских умов» - предшественников Шекспира [Электронный ресурс] // Энциклопедия «Мир Шекспира». URL: http://world-shake.ru/ru/Encyclopaedia/ 4136.html [архивировано в WaybackMachine] (дата обращения: 23.05.2018).

Луков, Вл. А. (2014) Концепция тезаурусных сфер // Знание. Понимание. Умение. № 1. С. 307-326.

Луков, Вл. А. (2018) Европейская культура в русском тезаурусе: Энциклопедические очерки : в 3 т. / под общ. ред. В. А. Лукова ; редкол.: Вал. А. Луков (сост., отв. ред.), Н. В. Захаров, В. Кофлер, Т. Ф. Кузнецова, В. П. Трыков. М. : Изд-во Моск. гуманит. ун-та. Т. 1.560 с.

Львов, К. (2016) «Добро и разум изгнаны за дверь» [Электронный ресурс]// Радио Свобода. 11 сентября. URL: https://svoboda.org/a/27970305.html [архивировано в WaybackMachine] (дата обращения: 23.05.2018).

Bassett, K. (2014) Shakespeare in Love at the Noel Coward Theatre [Электронный pecypc] // The Times. July 23. URL: https://www.thetimes.co.uk/article/shakespeare-in-love-at-the-noel-coward-theatre9svgq60mpsl (дата обращения: 23.05.2018).

Billington, M. (2014) Shakespeare in Love review — a heady celebration of the act of theatre [Электронный ресурc] // The Guardian. July 24. URL: http://theguardian.com/culture/2014/jul/24/shakespeare-in-love-theatre-review [apхивировано в WaybackMachine] (дата обращения: 23.05.2018).

Cain, S. (2014) Shakespeare in Love reviews — not Bard, but very good [Электронный ресурс] // The Guardian. July 24. URL: http://theguardian.com/ stage/2014/jul/24/shakespeare-in-love-reviews-not-bard-but-very-good [архивировано в WaybackMachine] (дата обращения: 23.05.2018).

Dugdale, J. (2016) How close were Marlowe and Shakespeare? [Электронный pecypc] // The Guardian. October 28. URL: https://theguardian.com/books/booksblog/2016/oct/28/brush-up-marlowe [архивировано в WaybackMachine] (дата обращения: 23.05.2018).

Letts, Q. (2014) Bard with a touch of Blackadder in this skittish delight [Электронный pecypc] // Daily Mail Online. July 24. URL: http://dailymail.co.uk/tvshowbiz/article-2703465/Bard-touch-Blackadder-skittishdelight-QUENTIN-LETTS-night-review.html [архивировано в WaybackMachine] (дата обращения: 23.05.2018).

Purves, L. (2014) Shakespeare in Love - Noel Coward Theatre SW1 [Электронный ресурс] // Theatrecat. July 24. URL: http://theatrecat.com/2014/ 07/24/shakespeare-in-love-noel-coward-theatre-sw1/ [архивировано в WaybackMachine] (дата обращения: 23.05.2018).

Spencer, Ch. (2014) Shakespeare in Love, review: 'The best British comedy since One Man, Two Guvnors’ [Электронный pecypc] // The Telegraph. 2014. Ju- 
ly 23. URL: http://telegraph.co.uk/culture/theatre/theatre-reviews/10983777/Shakespeare-in-Love-review-the-best-British-comedy-since-One-Man-Two-Guv-nors. html [архивировано в WaybackMachine] (дата обращения: 23.05.2018).

Taylor, P. (2014) Shakespeare in Love, Noel Coward Theatre, review: Deliciously funny and absurd [Электронный ресурс] // The Independent. July 23. URL: http://independent.co.uk/arts-entertainment/theatre-dance/reviews/shakespeare-in-love-noel-coward-theatre-review-deliciously-funny-and-absurd-9623905. html [архивировано в WaybackMachine] (дата обращения: 23.05.2018).

Дата поступления: 25.05.2018 г.

Захаров Николай Владимирович - доктор философии $(\mathrm{PhD})$, кандидат филологических наук, директор Шекспировского центра Института фундаментальных и прикладных исследований Московского гуманитарного университета, академик Международной академии наук (IAS, Инсбрук, Австрия), ученый секретарь Шекспировской комиссии РАН. Адрес: 111395, Россия, г. Москва, ул. Юности, 5, корп. 6. Тел.: +7 (499) 374-75-95. Эл. адрес: nikoltine@yandex.ru

Zakharov Nikolay Vladimirovich, PhD, Candidate of Philology; Director, Shakespeare Centre, Institute of Fundamental and Applied Studies, Moscow University for the Humanities; full member, International Academy of Science (Innsbruck, Austria); Academic Secretary, Shakespeare Committee, Russian Academy of Sciences. Postal address: Bldg. 6, 5 Yunosti St., 111395 Moscow, Russian Federation. Tel.: +7 (499) 374-75-95. E-mail: nikoltine@yandex.ru

\section{Для циттирования:}

Захаров Н. В. Образ Кристофера Марло и псевдобиографический подход в современной массовой культуре [Электронный ресурс] // Горизонты гуманитарного знания. 2018. № 3. C. 62-71. URL: http://journals.mosgu.ru/ggz/ article/view/798 (дата обращения: дд.мм.гггг). DOI: 10.17805/ggz.2018.3.4 